\title{
The Application of Isolated Building in Wenchuan after Wenchuan Earthquake
}

\author{
Jian-Min JIN ${ }^{1, a}$, Ping TAN ${ }^{2, b}$, Chao-Yong SHEN ${ }^{3, c}$ \\ ${ }^{1,2,3}$ Earthquake Engineering Research \& Test Center, Guangzhou University, Guangzhou, 510405, \\ P.R.China \\ ajinjianmin152@aliyun.com, bptan@gzhu.edu.cn, 'shenchaoyong72@yahoo.com.cn
}

Keywords: Isolatied Building, Isolation Design, Isolatied Building Construction.

\begin{abstract}
The paper introduces the application of isolated building in Wenchuan after Wenchuan earthquake. In the isolation design of the Second Primary School, combination isolation technology and viscous dampers were used to reduce the earthquake response of the upper structure, the upper structure can reduce 1 degree to design and the structure and human security can be protected in the earthquake. Finally, through construction rules and process of the project, discuss of the isolated building construction is conducted.
\end{abstract}

\section{Introduction}

Wenchuan earthquake on May 12, 2008, larger than the Tangshan earthquake in magnitude and earthquake affected area, caused extensive damage in Sichuan and neighboring provinces and cities. Its influence spread to most parts of our country. Most collapsed rural buildings have not earthquake resistant design. A lot of frame structures have not serious damage, but the destruction of the decoration, functional disruption caused some losses. Many masonry structure with large bay destroyed, In mixing system of masonry structure and reinforced concrete, brick masonry seriously damaged. Especially in schools, serious casualties caused by collapsed buildings [1,2]. Visibly, the traditional seismic design can not ensure the structural and non structural components, personal and equipment safety in the earthquake. Base isolated building has been applied in 1980s. In 1993, Zhou Fulin presided at design of the first isolated building ( 8 stories) in Shantou, China, using laminated rubber bearings[3]. In some previous earthquakes, isolated buildings, which have excellent isolation effect, safeguard architecture and human safety during the earthquake, so the seismic isolation technology obtained the rapid development.

\section{Isolation Design of Wenchuan County Second Primary School}

In order to improve the seismic safety of building, the Wenchuan County Second Primary School was used base isolation technology, which has three teaching buildings and two dormitories. Teaching buildings and dormitories are reinforced concrete frame structure. No. 1 and No. 3 teaching building are 3 -story and $11.8 \mathrm{~m}$ in height. No. 2 teaching building is 5 -story and $19.0 \mathrm{~m}$ in height. No. 3 teaching building is 5-story and $19.0 \mathrm{~m}$ in height. Dormitory A and B are 7-story and $26.1 \mathrm{~m}$ in height. The project is of seismic intensity 8 protection, site Class II, characteristic period $0.35 \mathrm{~s}$. Fault within $5 \mathrm{~km}$, the influence coefficient of near field is taken as 1.5. According to the relevant provisions of the code for seismic design of buildings[4]. El Centro (NS), Taft (EW) and 1 artificial wave $(\mathrm{Tg}=0.35 \mathrm{~s})$ are used as input waves. The peak accelerations of seismic wave are $0.105 \mathrm{~g}$ (frequent earthquake) and $0.60 \mathrm{~g}(\mathrm{rare}$ earthquake).

As the buildings are under 7 stories, especially, the No. 3 teaching building is only 3 stories and smaller axial spacing, using rubber isolator (diameter $700 \mathrm{~mm}$, the average pressure is only $4.77 \mathrm{MPa}$, post yield period $\mathrm{Tf}=2.63 \mathrm{~s}$ ), will not be able to reach the objective of reducing 1 degree, and the rubber bearing with small diameter will not be able to meet the large displacement of isolation layer during rare earthquake. So, the combination of the rubber bearings(diameter $700 \mathrm{~mm}$ )and the elastic sliding bearing (friction coefficient,0.04,as shown in Fig. 1) are used, the post yield period Tf extends for more than 3.5s, which can reduce 1 degree in design of the buildings and control displacement of isolation layer at the same time. 


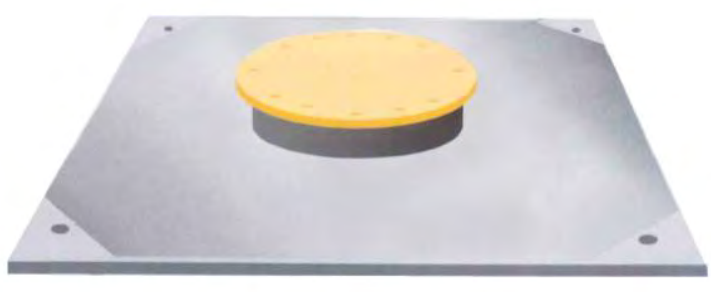

Fig. 1 Elastic Slide Bearing

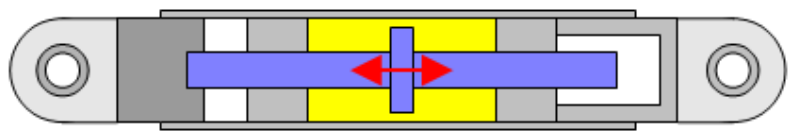

Fig. 2 Viscous Damper

The isolation rubber bearing layout of the teaching building and dormitory are shown in Fig. 3 and Fig. 4. In order to further improve the damping effect and effectively control the displacement of isolation layer, the isolation layer used the rubber bearings, the elastic sliding bearing and viscous oil damper. The teaching buildings used a total of 65 bearings, 46 rubber bearing $(\mathrm{G}=0.392 \mathrm{MPa}), 19$ elastic sliding bearing $(\mathrm{G}$ of the rubber parts is $0.392 \mathrm{MPa}$, and diameter of the rubber parts are $300 \mathrm{~mm}, 400 \mathrm{~mm}, 500 \mathrm{~mm}$ and $600 \mathrm{~mm}$ ), bearing type and number are shown in Table 1 . The dormitory buildings using a total of 69 bearings, 42 rubber bearings, 27 elastic sliding bearings (diameter of the rubber parts are $300 \mathrm{~mm}$, $500 \mathrm{~mm}$ and $600 \mathrm{~mm}$ ), 8 viscous oil damper (damping force, $500 \mathrm{kN}$, as shown in Fig.4), bearing type and number are shown in Table 2.The average compression stress of the rubber bearings of the teaching building is from $3.87 \mathrm{MPa}$ to $6.81 \mathrm{MPa}$, and the elastic sliding bearing is from $6.98 \mathrm{MPa}$ to $15 \mathrm{MPa}$. The average compression stress of the rubber bearings of the dormitory is from $4.35 \mathrm{MPa}$ to $6.63 \mathrm{MPa}$, and the elastic sliding bearing is from $5.53 \mathrm{MPa}$ to $16.85 \mathrm{MPa}$. The rubber bearings, the elastic sliding bearings and the damper, have maximum deformation capacity of $500 \mathrm{~mm}$. The isolation structure under the design wind loads, isolated layer should not generate the horizontal displacement, which requires the design wind load value of isolated structure should be less than the total yield stress of the bearings. The wind load calculation of the teaching building and dormitory can satisfy the requirements.

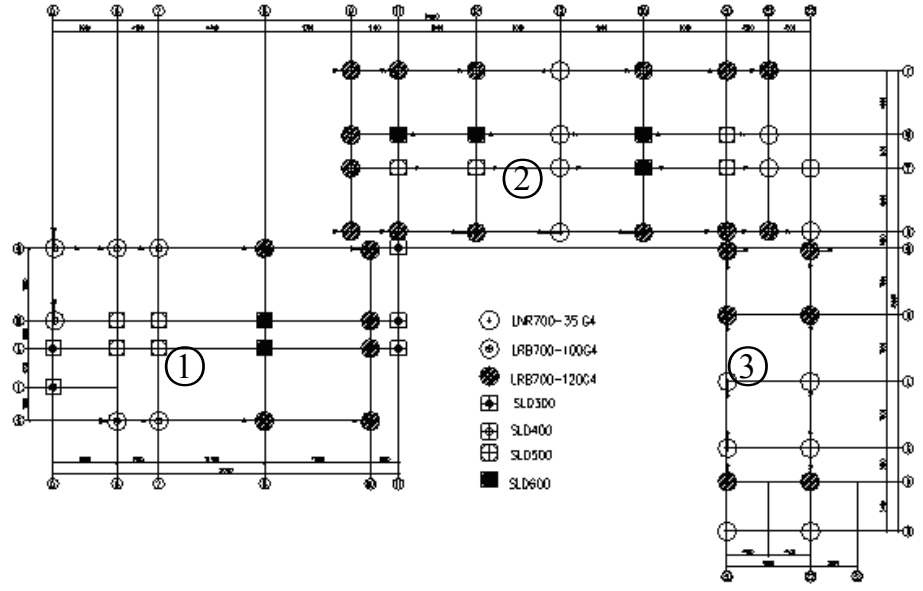

Fig. 3 Isolation Layer Plan of Teaching Build

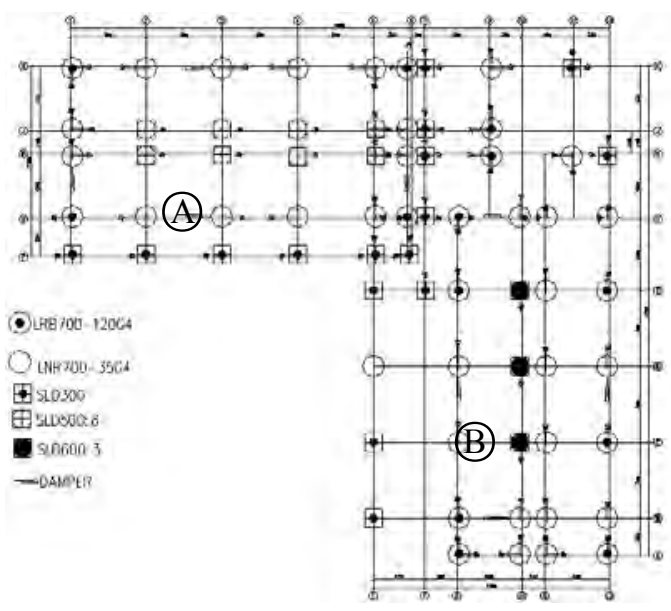

Fig. 4 Isolation Layer Plan of Dormitory

Under frequent earthquake, Shear force ratio between isolation structure and non-isolated structure are $0.299,0.348,0.278,0.349$ and 0.342 (No. 1, No. 2,No. 3 teaching building, dormitory A and B), respectively, which are less than 0.35 . Horizontal seismic reduction factor can be 0.5 . The horizontal earthquakes of superstructure can drop 1 degrees to calculate.

Under rare earthquake, the story drift angle of the superstructure(No. 1, No. 2,No. 3 teaching building, dormitory $\mathrm{A}$ and $\mathrm{B}$ ), are 1/384, 1/338, 1/347, 1/319 and 1/261 respectively. which meet the requirement of the structure elastic-plastic story drift angle in the code. The displacement of isolation layer (No. 1, No. 2, No. 3 teaching building, dormitory A and B), 275mm, 270mm, 264mm, 255mm and $323 \mathrm{~mm}$ respectively. which less than the maximum permissible displacement $375 \mathrm{~mm}$. Time history analysis showed that for El Centro, Taft and artificial wave, input in $\mathrm{X}$ or $\mathrm{Y}$ direction, The consumption of isolation layer energy to input energy is above $90 \%$. 
Tab. 1 The Isolation Bearings of the Teaching Building Tab. 2 The Isolation Bearings of the Dormitory

\begin{tabular}{ccccc}
\hline Type & $\begin{array}{c}\text { diameter } \\
(\mathrm{mm})\end{array}$ & $\begin{array}{c}\text { Tr } \\
(\mathrm{mm})\end{array}$ & $\begin{array}{c}\text { Total height } \\
(\mathrm{mm})\end{array}$ & Number \\
\hline LNR700-35G4 & 700 & 140 & 315 & 14 \\
LRB700-100G4 & 700 & 140 & 315 & 6 \\
LRB700-120G4 & 700 & 140 & 315 & 26 \\
SLD300 & 300 & 21 & 137 & 5 \\
SLD500 & 500 & 20 & 142 & 8 \\
SLD600 & 600 & 20 & 139 & 6 \\
\hline
\end{tabular}

\begin{tabular}{ccccc}
\hline Type & $\begin{array}{c}\text { diameter } \\
(\mathrm{mm})\end{array}$ & $\begin{array}{c}\text { Tr } \\
(\mathrm{mm})\end{array}$ & $\begin{array}{c}\text { Total height } \\
(\mathrm{mm})\end{array}$ & Number \\
\hline LNR700-35G4 & 700 & 160 & 347 & 29 \\
LRB700-120G4 & 700 & 160 & 347 & 13 \\
SLD300 & 300 & 21 & 137 & 16 \\
SLD500 & 500 & 20 & 142 & 8 \\
SLD600 & 600 & 20 & 139 & 3 \\
LNR700-35G4 & 700 & 160 & 347 & 29 \\
\hline
\end{tabular}

\section{Construction of Wenchuan County Second Primary School}

Must be familiar with the design and construction plans before construction, after the bearins arrival, quantity, specification and size should be checked. Construction schedule of isolation device should be prepared before construction.

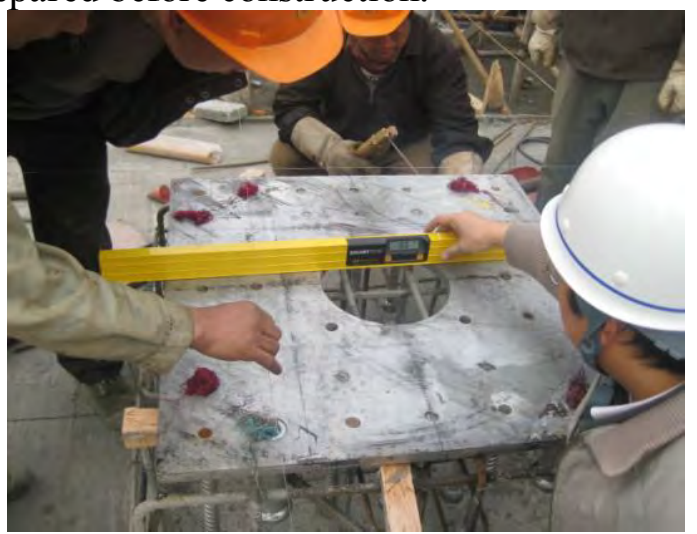

Fig. 5 Level Measurement of the Embedded Board

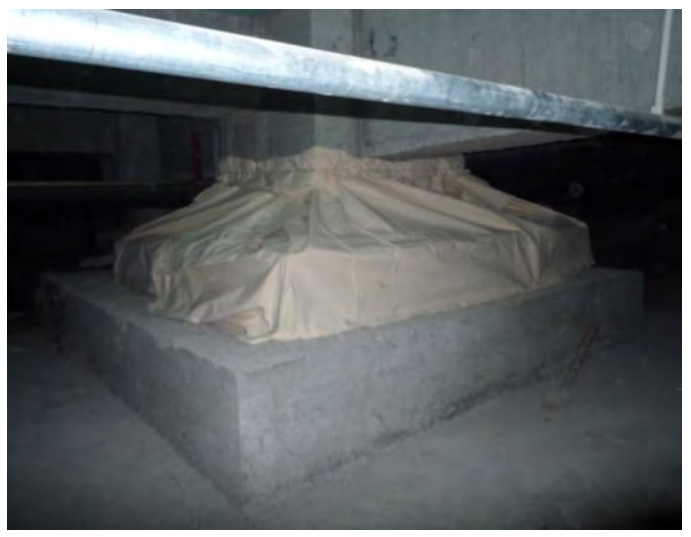

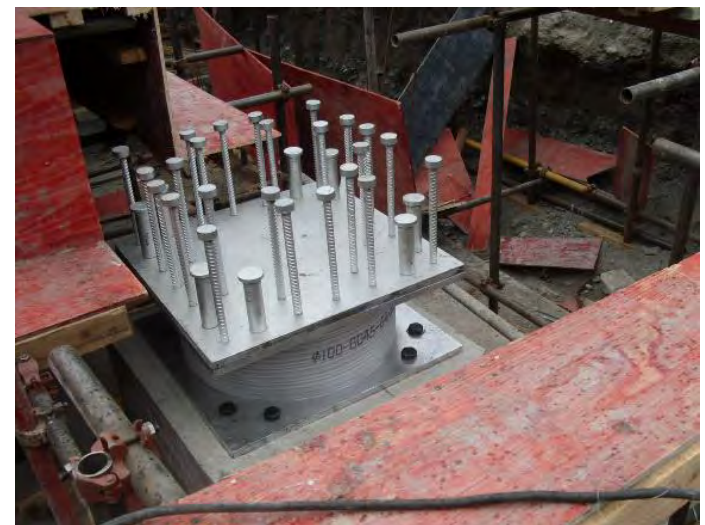

Fig. 6 Installed Rubber Bearing on the Buttress

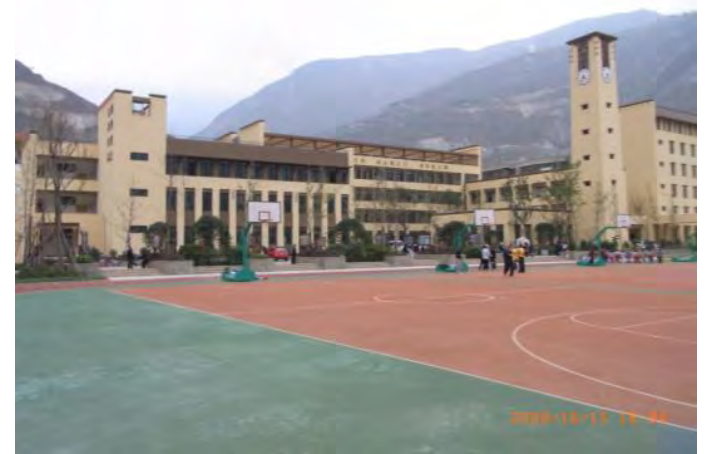

Fig. 7 The Dust Protection Measures of the Elastic Slide Bearing Fig. 8 Architectural Appearance

The top level error of buttress should not be greater than 5\%.After the bearing installation, the top level error of bearings should not be greater than $8 \%$; deviation of the plane position location of isolation bearing center should be less than $5.0 \mathrm{~mm}$. Deviation of elevation of isolation bearing center should be less than $5.0 \mathrm{~mm}$. Isolation bearing connecting plate and the exposed bolt should take rust protective measures. High strength bolts should be symmetrical tightening, and tightening process is divided into primary screw, double screw and final screw, which is in the same day. Double torque is equal to the primary tightening torque, the primary tightening torque should be the $50 \%$ of the final tightening torque. The torque wrench for the high strength bolt and the checking used in each class, should be corrected before the operation, and the torque error are $5 \%$ and $3 \%$. 
In the bearing installed stage, the top surface level of the buttress and the isolator were observed and recorded, and the isolator center plane position and elevation also be observed and recorded .The top level error of embedded plate is less than 5\%. Level measurement of embedded board is shown in Fig.5.The isolator should be installed after waiting for concrete strength of the buttress reaches $75 \%$ of design strength, to prevent concrete damage in the installation process. Installed rubber bearing on the buttress is shown in Fig.6. In the construction stage, the bearings should be temporary covered for protection, and the vertical deformation of isolation bearing should be observe and record. In the project construction is completed, the clearance of upper structure, the isolation layer component and the surrounding should be checked and recorded. Sliding panel of elastic sliding bearings should be dust-proof protective measures is durable and removable, shown in Fig.7. After completion, architectural appearance is shown in Fig.8.

\section{Summary}

The paper introduces isolated building applications in Wenchuan after "5.12" earthquake. Combined isolation, which consist of rubber bearing and elastic sliding bearing, is used to the low rise building, and in order to further improve the isolation effect, the combined isolation rubber bearing, the elastic sliding bearings and viscous oil damper were used for dormitory building of second primary school. The isolation design of Wenchuan Second Primary School shows that base isolation can effectively reduce the earthquake action of superstructure. China has production capacity of all kinds of isolation devices, basically. Design and application ability has been comparatively mature, but need to be formed, refine the relevant standards, norms and so on. With the development of increasing isolation building and isolation product, it is necessary to refine the relevant base isolated building construction and acceptance criteria.

\section{Acknowledgements}

This work was financially supported by National Science \& Technology Pillar Program in the $12^{\text {th }}$ Five-year Plan of China (2012BAJ07B02), Natural Science Foundation of China under Major Program No. 91315301-07 and National Basic Research Program of China (2012CB723304) .This support is gratefully acknowledged.

\section{References}

[1]GUO Xun. Characteristics and mechanism analysis of the great Wenchuan earthquake[J]. China Earthquake Engineering and Engineering Vibration, 2009, 29 (6):74-87(in Chinese.)

[2]LI Ying-min, HAN Jun, LIU Li-ping ZHENG Ni-na WANG Li-ping LIU Jian-wei. Investigation and analysis of masonry building damage caused by the $5 \cdot 12$ Wenchuan earthquake, Sichuan Province[J]. China Journal of Xi' an University of Architecture\&Technology2009,41 (5):606-611 (in Chinese).

[3]Zhow Fulin. Seismic control of structures. Beijing: Seismological Press, 1997. (in Chinese).

[4]GB 50011-2001 Code for seismic design of buildings[S]. Beijing: China Architecture \& Building Press, 2008. (in Chinese). 